\title{
Study on Rapid Start-up of Anammox Process under the Influence of Magnetic Field
}

\author{
Jiabin Wang ${ }^{1, *}$, Cong Yu ${ }^{1}$,Shoubin Zhang ${ }^{1}$, Tianhang Li $^{1}$, Dong Zhang ${ }^{1}$, Xiaoyu Wang ${ }^{1}$ \\ ${ }^{1}$ School of Civil Engineering \& Architecture, University of Jinan, NO.336, Nanxinzhuang West Road., Jinan 250022, P.R.China
}

\begin{abstract}
In order to study the rapid start-up technology of the anaerobic ammonium oxidation process, a comparison test of no magnetic field and magnetic field was performed in two identical ASBR reactors R1 and R2 respectively. The results show that both reactors can successfully start Anammox. The R2 start-up period (75d) of the applied magnetic field is shortened by 15\% compared with the unloaded magnetic field R1 start-up period (90d); the R2 ammonia-nitrogen removal rate is $97 \%$ higher than that of $95 \%$ of R1. The quantitative relationship analysis between $\mathrm{NH}_{4}{ }^{+}-\mathrm{N}, \mathrm{NO}_{2}{ }^{-}-\mathrm{N}$ and $\mathrm{NO}_{3}{ }^{-}-\mathrm{N}$ shows that the change of $\mathrm{R} 2$ ratio is closer to the theoretical value, which can better improve the activity of microbial enzymes and accelerate the enrichment of ammonia oxidizing bacteria in the reactor. It is beneficial to nitrogen removal and R2 can quickly start the anaerobic ammonium oxidation process.
\end{abstract}

\section{Introduction}

The traditional biological nitrogen removal process is mainly realized by a nitrification-denitrification process. However, there are problems such as a large amount of aeration and high demand for carbon sources, which increase the operation cost of the whole process $[1 ; 2]$. Anammox is a new type of biological nitrogen removal technology, which is suitable for treating high ammonia nitrogen and low $\mathrm{C} / \mathrm{N}$ wastewater. Its basic principle is that Anammox oxidizes $\mathrm{NH}_{4}{ }^{+}-\mathrm{N}$ to $\mathrm{N}_{2}$ with $\mathrm{NO}_{2}{ }^{-}-\mathrm{N}$ as an electron acceptor [2-4]. The strain belongs to the autotrophic anaerobic type, which can save the cost of organic carbon source and aeration compared with the traditional denitrification process. However, the generation cycle of Anammox bacteria is long and sensitive to environmental conditions, resulting in a long cycle of the Anammox process, which seriously restricts the wide application of the process [5-8].

Studies have shown that magnetic fields can affect the activity of microbial enzymes, increasing the activity of catalase, peroxidase and three phosphatases $[9 ; 10]$. Wang Qiang [11] found that the maximum removal rate of ammonia nitrogen appeared in the magnetic field intensity of $60 \mathrm{mT}$, the removal rate of ammonia nitrogen reached $93 \%$. This paper intends to investigate the start-up and operation performance of the Anammox process under the influence of magnetic field, and provides a theoretical basis for the rapid start of anaerobic ammonium oxidation.

\section{Materials and methods}

\footnotetext{
* Corresponding author: cea_wangjb@ujn.edu.cn
}

\subsection{Experimental Equipment}

The test uses two identical ASBR reactors, reactor R1 (without magnetic field), reactor R2 (with magnetic field), and the reactor is made of organic glass (Fig. 1). The reactor is $1200 \mathrm{~mm}$ high and $100 \mathrm{~mm}$ in diameter. Each group of devices is equipped with a water inlet, a water outlet, a temperature controller, and a reaction gas circulation agitating intake pipe, and the reaction device is wrapped with black material to avoid light.

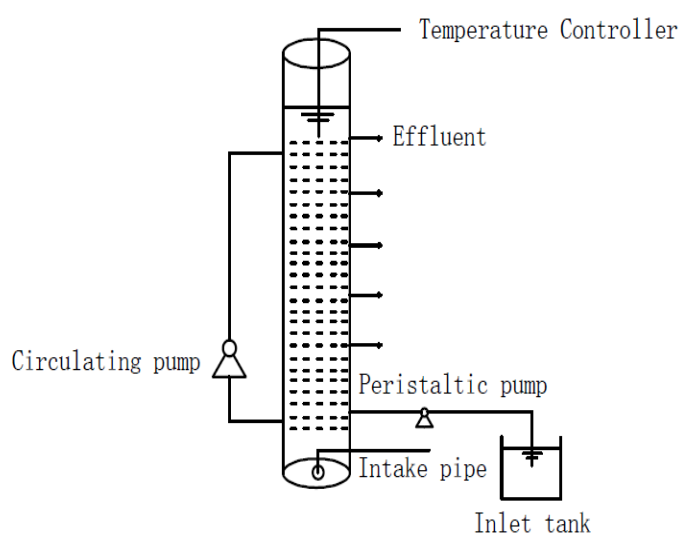

Fig. 1. The schematic diagram of the ASBR used in this study.

\subsection{Influent water quality and inoculated sludge}

The test influent is simulated sewage, formulated with $\mathrm{NaNO}_{2}$ and $\mathrm{NH}_{4} \mathrm{Cl}$.Other components include: $\mathrm{KH}_{2} \mathrm{PO}_{4}$, $\mathrm{MgSO}_{4} .7 \mathrm{H}_{2} \mathrm{O}, \mathrm{NaHCO}_{3}$, etc. The trace elements are provided by garden leachate. During the test, the $\mathrm{pH}$ was adjusted by adding $\mathrm{NaOH}$. The prepared sewage was 
purged with nitrogen to remove dissolved oxygen in the water, and the aeration time was $15 \mathrm{~min}$. The test inoculated sludge was denitrified sludge from a reclaimed water station in Jinan, and the inoculated sludge was diluted with distilled water to $3500 \mathrm{mg} / \mathrm{L}$.

\subsection{Operation method}

The test was carried out in two identical ASBR reactors as shown in Figure 1. The reactor without a magnetic field was set to $\mathrm{R} 1$, and the reactor to which the magnetic field was applied was set to R2. The inoculated sludge is denitrified sludge from a moderate water station in Jinan. Before inoculation, deionized water is used to wash, dilute and stand. The ammonia concentration of influent increased from $40 \mathrm{mg} / \mathrm{L}$ to 70 $\mathrm{mg} / \mathrm{L}$, and the concentration of nitrite increased from $40 \mathrm{mg} / \mathrm{l}$ to $80 \mathrm{mg} / \mathrm{L}$. The temperature of the reactor was controlled at $30{ }^{\circ} \mathrm{C}$ and $\mathrm{pH}$ was controlled between 7.58.5 , the operating period of the reactor was $48 \mathrm{~h}$, and the drainage was 40 hours per time.

Zhang Dong [12] showed that the addition of magnetic particles in the ASBR reactor of $30 \mathrm{~g} / \mathrm{L}$ can accelerate the enrichment of Anammox bacteria, which consists of titanate coupling agent, polyvinyl alcohol / Sodium alginate bonding agent, nanometre $\mathrm{Fe}_{3} \mathrm{O}_{4}$ addition amount of $5 \%$, Grain size of $2 \mathrm{~mm}$, magnetization time of $60 \mathrm{~min}$ is the optimal preparation condition, and its magnetic field strength is stable at $0.75 \mathrm{mT}$ after $30 \mathrm{~d}$ decay.

\subsection{Analytical method}

The test methods for the influent and effluent water quality of the reactor are as follows: NH4+-N is determined by Nessler's reagent spectrophotometry (Shimadzu, UV-2700), and $\mathrm{NO}_{2}^{-}-\mathrm{N}$ is determined by $\mathrm{N}-$ (1 naphthyl)- Determination of ethylenediamine by spectrophotometry(Shimadzu, UV-2700), $\mathrm{NO}_{3}{ }^{-}-\mathrm{N}$ was determined by ion chromatography (Dionex, ICS-1000). The TN concentration is expressed as the sum of the concentrations of $\mathrm{NH}_{4}^{+}-\mathrm{N}, \mathrm{NO}_{2}^{-}-\mathrm{N}$ and $\mathrm{NO}_{3}^{-}-\mathrm{N}$, and $\mathrm{pH}$ is determined by portable multi-parameter analyzer (Hach, HQ40d).

\section{Results and discussion}

\subsection{Anaerobic ammonium oxidation start-up phase}

The denitrification performance of R1 without magnetic field and R2 reactor with magnetic field in the start-up phase is shown in the figure below. According to the variation rule of $\left(\mathrm{NH}_{4}{ }^{+}-\mathrm{N}, \mathrm{NO}_{2}^{-}-\mathrm{N}, \mathrm{NO}_{3}{ }^{-}-\mathrm{N}\right)$, the start-up process is divided into three steps: Active lag (1-20d), activity improvement (20d-60d), active stability period (60d-100d).

In the active lag period (within 10 days), the removal rate of ammonia nitrogen in the reactors $\mathrm{R} 1$ and $\mathrm{R} 2$ is almost zero, the removal rate of nitrite nitrogen is over
$90 \%$, and the concentration of effluent nitrate nitrogen is almost zero. When running for 20 days, the removal rate of ammonia nitrogen reached about $10 \%$, and the effluent nitrate nitrogen in R1 and R2 is $10 \mathrm{mg} / \mathrm{L}$. Due to the lack of oxygen and organic matter in the reactor, the heterotrophic aerobic bacteria are autolyzed due to changes in environmental conditions $[2 ; 13]$, and the release of nitrogen-containing organic matter by autolysis causes ammonia nitrogen accumulation, due to denitrification, Partial ammonia nitrogen and nitrite nitrogen were converted to nitrate nitrogen, which resulted in the basic removal of nitrite nitrogen.

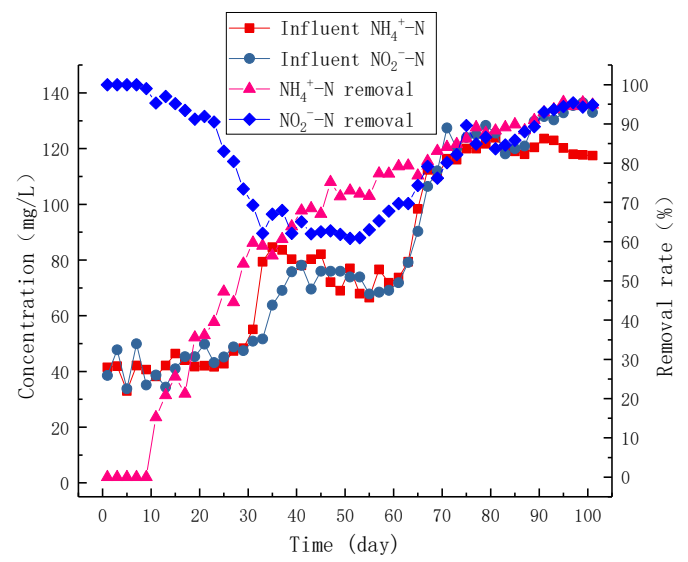

Fig. 2. Denitrification performance of Anammox reactor R1.

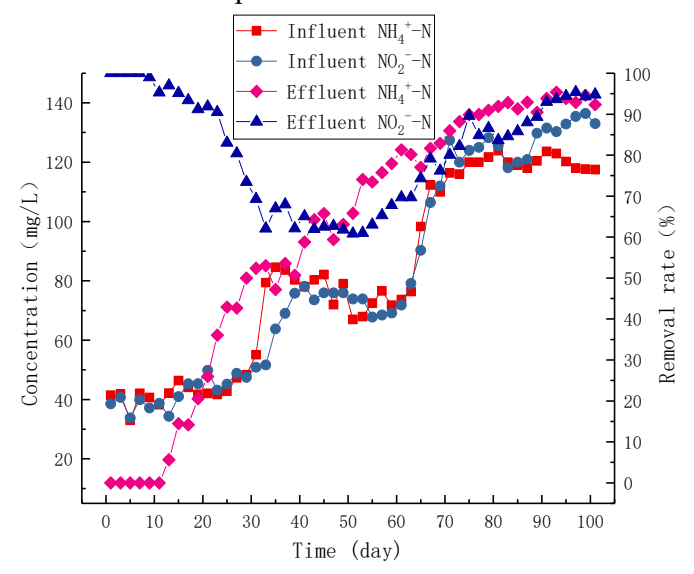

Fig. 3. Denitrification performance of Anammox reactor R2.

During the activity improvement period (20d-60d), the influent ammonia nitrogen and the influent nitrite nitrogen concentration were increased to $80 \mathrm{mg} / \mathrm{L}$ at $35 \mathrm{~d}$. When the influent nitrate nitrogen concentration was increased to $25 \mathrm{mg} / \mathrm{L}$, the effluent nitrate nitrogen concentration was stable at $50 \mathrm{mg} / \mathrm{L}$. In the R1 and R2 reactors, the removal rate of ammonia nitrogen reached about $80 \%$, and the removal rate of nitrite nitrogen decreased to about $65 \%$. This indicates that the denitrification is gradually weakening at this stage, because the organic matter released by the heterotrophic bacteria gradually decreases, causing the denitrifying bacteria to have insufficient supply of organic carbon, resulting in death, which is beneficial to the growth of Anammox bacteria.

During the active stabilization period (60d-100d), the influent ammonia nitrogen and influent nitrite nitrogen of the reactors R1 and R2 gradually increased, and the 
R1 and R2 ammonia nitrogen removal rates reached 90\% at $90 \mathrm{~d}$ and $75 \mathrm{~d}$ respectively, and finally stabilized above $95 \%$; the removal rate of nitrite nitrogen reached more than $90 \%$ at $90 \mathrm{~d}$ and $75 \mathrm{~d}$ respectively, and finally stabilized at $95 \%$ or more. The effluent nitrate nitrogen in the R1 and R2 reactors gradually increased to about $85 \mathrm{mg} / \mathrm{L}$ at $80 \mathrm{~d}-100 \mathrm{~d}$, and the nitrite nitrogen can survive with a small amount of dissolved oxygen in the water. It marks the successful start of the Anammox reactor.

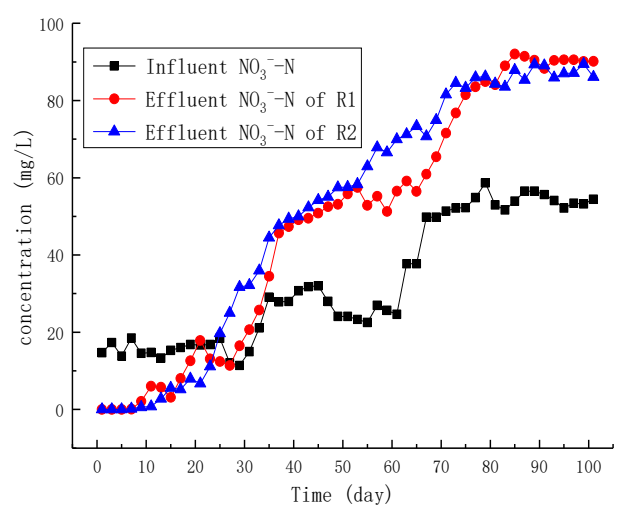

Fig. 4. Denitrification performance of Anammox reactor R1, R2.

\subsection{Changes in stoichiometry of anaerobic ammonium oxidation}

During the steady operation of the Anammox reactor, $\mathrm{NH}_{4}{ }^{+}-\mathrm{N}$ and $\mathrm{NO}_{2}{ }^{-}-\mathrm{N}$ were simultaneously removed. Mulder A [14] and other believe that the energy of fixed $\mathrm{CO} 2$ and the conversion of $\mathrm{NO}_{2}^{-}-\mathrm{N}$ to $\mathrm{NO}_{3}^{-}-\mathrm{N}$ during Anammox process, the yield of $\mathrm{NO}_{3}{ }^{-} \mathrm{N}$ reflects the increase of Anammox bacteria. Therefore, according to the Anammox reaction equation [5], the theoretical values of $\mathrm{NO}_{2}{ }^{-}-\mathrm{N}$ consumption/ $\mathrm{NH}_{4}{ }^{+}-\mathrm{N}$ consumption and $\mathrm{NO}_{3}{ }^{-}-\mathrm{N}$ production/ $\mathrm{NH}_{4}{ }^{+}-\mathrm{N}$ consumption are 1.32 and 0.26 respectively. $\mathrm{R} 1, \mathrm{R} 2$ reactor $\Delta \mathrm{NO}_{3}{ }^{-} \mathrm{N} / \Delta \mathrm{NH} 4+-$ $\mathrm{N}, \Delta \mathrm{NO}_{2}{ }^{-}-\mathrm{N} / \Delta \mathrm{NH}_{4}{ }^{+}-\mathrm{N}$ during stable operation of the reactor at $60-100 \mathrm{~d}$.

As shown in Fig. 5, the ratio of $\Delta \mathrm{NO}_{3}{ }^{-}-\mathrm{N} / \Delta \mathrm{NH}_{4}{ }^{+}-\mathrm{N}$ in the R1 and R2 reactors of the $60 \mathrm{~d}-67 \mathrm{~d}$ sharply decreased and recovered, and then stabilized at about 0.30 , which was higher than the theoretical value of 0.26 . At $60 \mathrm{~d}-100 \mathrm{~d}$, the values of $\Delta \mathrm{NO}_{2}{ }^{-}-\mathrm{N} / \Delta \mathrm{NH}_{4}{ }^{+}-\mathrm{N}$ in the R1 and $\mathrm{R} 2$ reactors gradually increased to around 1.2 . In the anaerobic ammonium oxidation reactor, a small amount of aerobic ammonia oxidizing bacteria can survive in the reactor with a small amount of oxygen, converting ammonia nitrogen into nitrite nitrogen and nitrite nitrogen is oxidized to nitrate nitrogen [15]. Observing the change of $\mathrm{R} 1$ and $\mathrm{R} 2$ ratios, it is found that the magnetized $\mathrm{R} 2$ reactor is closer to the theoretical value. It can be inferred that the Anammox reaction in the R2 reactor accounts for a higher proportion, indicating that the magnetic field can effectively enhance the activity of Anammox bacteria and accelerate the start of the Anammox process.

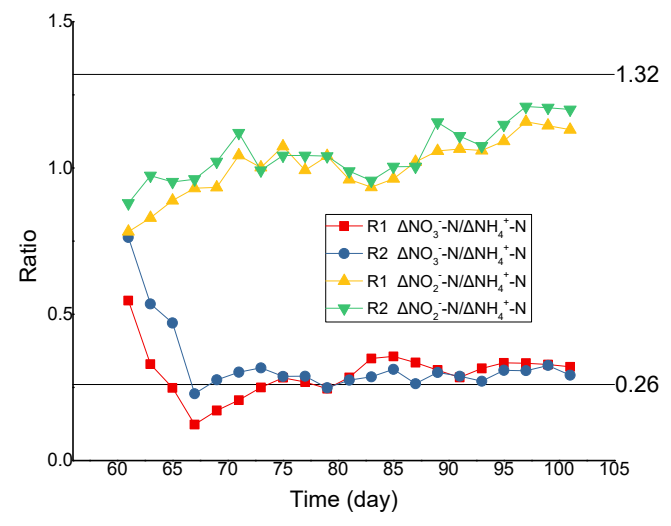

Fig. 5. Changes in stoichiometry of Anammox.

\section{Conclusions}

(1)In the start-up phase of the Anammox reaction, the start-up time of the magnetized reactor R2 is shorter than that of the un-energized reactor R 1 by 25 days, where in the reactor $\mathrm{R} 1$ and $\mathrm{R} 2$ have a removal rate of about $95 \%$ for the ammonia nitrogen. The removal rate of ammonia nitrogen in R1 $(95 \% \pm 1 \%)$ was lower than that in R2 (97 $\pm 1 \%)$. The removal rate of nitrite nitrogen in $\mathrm{R} 1$ (95 $\pm 1 \%$ ) was lower than that in R2 (98 $\pm 1 \%)$.

(2) In the stable operation stage of the Anammox reactor, the ratio of $\Delta \mathrm{NO}_{3}{ }^{-}-\mathrm{N} / \Delta \mathrm{NH}_{4}{ }^{+}-\mathrm{N}$ in the $\mathrm{R} 1$ and $\mathrm{R} 2$ reactors drops sharply, then rises and then stabilizes at around 0.30 , slightly higher than the theoretical value of 0.26 ; while the ratio of $\Delta \mathrm{NO}_{2}{ }^{-}-\mathrm{N} / \Delta \mathrm{NH}_{4}{ }^{+}-\mathrm{N}$ increased slowly, and finally stabilized at around 1.2 , lower than the theoretical value. However, the change of the two ratios of the $\mathrm{R} 2$ reactor is closer to the theoretical value, which indicates that the magnetic field can effectively increase the activity of the Anammox bacteria and accelerate the start of the Anammox process.

\section{Acknowledgment}

This work was supported by the Higher Education Science and Technology Plan of Shandong Province (J17KA198).

\section{References}

1. Ali M, Okabe S. Anammox-based technologies for nitrogen removal: Advances in process start-up and remaining issues[J]. Chemosphere, 141, 144-153 (2015)

2. Jetten M S, Strous M, Pas-Schoonen K T, Van De, et al. The anaerobic oxidation of ammonium[J]. Fems Microbiology Reviews, 22, 421-37 (1998)

3. Kuenen J G. Extraordinary anaerobic ammoniumoxidizing bacteria[J]. Asm News, 67, 456-463 (2001)

4. Schalk J, Oustad H, Kuenen J G, et al. The anaerobic oxidation of hydrazine: a novel reaction in 
microbial nitrogen metabolism[J]. Fems Microbiology Letters, 158, 61-67 (1998)

5. Strous M, Heijnen J J, Kuenen J G, et al. The sequencing batch reactor as a powerful tool for the study of slowly growing anaerobic ammoniumoxidizing microorganisms[J]. Applied Microbiology \& Biotechnology, 50, 589-596 (1998)

6. Kuenen J G. Anammox bacteria: from discovery to application[J]. Nature Reviews Microbiology, 6, 320-6 (2008)

7. Wr V D S, Abma W R, Blommers D, et al. Startup of reactors for anoxic ammonium oxidation: experiences from the first full-scale anammox reactor in Rotterdam[J]. Water Research, 41, 41494163 (2007)

8. Min P, Chon H T, Marton L. Mobility and accumulation of selenium and its relationship with other heavy metals in the system rocks/soils-crops in areas covered by black shale in Korea[J]. Journal of Geochemical Exploration, 107, 161-168 (2010)

9. Su Li, Yi Yanli, Jiao Ying, et al. Study on Magnetic effect of microbial and several enzyme activities in Brown soil [J]. Chinese Journal of Soil Science, 38, 957-961 (2007)

10. Ahn Y H. Sustainable nitrogen elimination biotechnologies: A review[J]. Process Biochemistry, 41, 1709-1721 (2006)

11. Cai Qing, Zhang Daijun, Xiao Pengying, et al. Influencing factors in completely autotrophic nitrogen removal process [J]. Chinese Journal of Environmental Engineering, 7, 3895-3900 (2013)

12. Zhang Dong. Study on the start up and operating characteristics of autotrophic nitrogen removal process enhanced by $\mathrm{NdFeB}$ magnetic particle [D]. University of Jinan, 1-71 (2017)

13. Chamchoi N, Nitisoravut S. Anammox enrichment from different conventional sludges[J]. Chemosphere, 66, 2225 (2007)

14. Mulder A, Graaf A a V D, Robertson L A, et al. Anaerobic ammonium oxidation discovered in a denitrifying fluidized bed reactor[J]. Fems Microbiology Ecology, 16, 177-184 (1995)

15. Dapena-Mora A, Hulle S W V, Campos J L, et al. Enrichment of Anammox biomass from municipal activated sludge: experimental and modelling results[J]. Journal of Chemical Technology \& Biotechnology Biotechnology, 79, 1421-1428 (2004) 